\title{
Een toets voor de beoordeling van verloskundige competentie
}

\author{
M.J.B. Govaerts, L.W.T. Schuwirth, C.P.M. van der Vleuten, A.K. Pin, M.E.J. Clement
}

\section{Samenvatting}

De laatste decennia bestaat in het hoger onderwijs veel aandacht voor de inrichting van het onderwijsleerproces en de manier waarop competentie van studenten en beroepsbeoefenaren beoordeeld kan worden. Groeiende ontevredenheid over traditionele toetsmethoden heeft in beroepsopleidingen geleid tot de invoering van toetsen waarin de beroepspraktijk zo dicht mogelijk wordt benaderd (authentieke toetsen of performance-based assessment). Het besef dat toetsing een van de belangrijkste factoren is in de sturing van het leergedrag van studenten is in deze ontwikkeling een belangrijke factor. Op basis van onderzoek en ontwikkelingen in het medisch onderwijs is aan de Vroedvrouwenschool te Kerkrade een toets ontwikkeld om verloskundige competentie van studenten in de opleiding te kunnen meten en beoordelen. In dit artikel wordt een beschrijving gegeven van deze Verloskundige CompetentieToets (VCT) en van de eerste ervaringen en ontwikkelingen voor de toekomst.

\section{Inleiding}

In Nederland wordt de bekwame beroepsuitoefening door beginnend verloskundigen gegarandeerd door de verloskundige opleidingen. De opleiding tot verloskundige duurt vier jaar. De opleidingen zijn zelf verantwoordelijk voor de kwaliteit van de kwalificerende examens op grond waarvan registratie als zelfstandig werkend eerstelijns verloskundige mogelijk is. Een voor de hand liggende vraag is dan of de bewijsvoering voor vakbekwaamheid aan de hand van de in de opleiding gebruikte toetsen wel voldoende krachtig is. Met andere woorden, zijn conclusies over competentie van studenten op basis van de gehanteerde toetsen wel voldoende gerechtvaardigd?

De aandacht voor kwaliteitseisen die gesteld moeten worden aan beroepsopleidingen en de examens die toelating geven tot de beroepsuitoefening is gedurende de laatste decennia sterk toegenomen. Deze belangstelling is voor een deel een gevolg van toenemende ontevredenheid over traditionele toetsmethoden. Er is een aantal redenen voor deze ontevredenheid aan te wijzen. ${ }^{1-3}$
1. Gehanteerde toetsmethoden zijn vaak onvoldoende representatief voor de beroepspraktijk. In veel beroepsopleidingen domineert toetsing van kennis. Niet zelden blijft deze kennistoetsing vervolgens beperkt tot het meten van reproductie van (feiten)kennis. Voor de meeste beroepsbeoefenaren geldt echter dat het beantwoorden van schriftelijke kennisvragen geen weerspiegeling vormt van hun dagelijks handelen. Vergelijkbare bezwaren kunnen aangevoerd worden tegen toetsing van geïsoleerde vaardigheden. Beperkte validiteit en relevantie voor de praktijk vormen daarmee belangrijke nadelen van deze toetsvormen.

2. Directe beoordeling van competentie van studenten kan plaatsvinden in de praktijk, tijdens stages. Stagebeoordelingen zijn echter vaak globale oordelen op basis van een beperkt aantal observaties door een beperkt aantal beoordelaars. Duidelijke richtlijnen en objectieve criteria voor de beoordeling ontbreken veelal, waardoor de betrouwbaarheid te wensen overlaat. 
3. Ten slotte sluiten beoordelingsmethoden in opleidingen vaak onvoldoende aan bij veranderde onderwijsconcepten, zoals probleemgestuurd onderwijs, competentiegericht onderwijs en doelstellingen als 'leren leren'. In onderwijs is het echter een bekend gegeven dat toetsing de belangrijkste sturende factor is in het leergedrag van studenten. ${ }^{4}$ Traditionele toetsmethoden sluiten vaak slecht aan op nieuwe onderwijsdoelstellingen; gewenst leergedrag wordt onvoldoende gestimuleerd, en het realiseren van onderwijsdoelstellingen kan zelfs belemmerd worden.

In veel beroepsopleidingen, en met name ook in het medisch onderwijs, heeft deze ontevredenheid geleid tot onderzoek naar meer valide toetsvormen voor beoordeling van competentie, die tegelijkertijd voldoende efficiënt en betrouwbaar zijn. 56 Deze ontwikkelingen worden gekenmerkt door een streven naar beoordeling van competentie in levensechte praktijksituaties, of in een simulatie die de beroepspraktijk zo dicht mogelijk benadert. Tegelijkertijd wordt daarbij gestreefd naar standaardisering van de toetscondities. ${ }^{7}$ Ontwikkelingen in het medisch onderwijs zijn daarbij toonaangevend gebleken voor andere opleidingen in de gezondheidszorg. 89 Aan de Vroedvrouwenschool (VVS) te Kerkrade werd, op basis van onderzoek en ontwikkelingen in het medisch onderwijs, een meer authentieke toets ontwikkeld voor de beoordeling van de competentie van student-verloskundigen. In dit artikel wordt een beschrijving gegeven van de ontwikkeling en invoering van deze Verloskundige CompetentieToets (VCT).

\section{Competentietoetsing: wat en hoe?}

De competentie van een beroepsbeoefenaar wordt in dit artikel gedefinieerd als de mate waarin deze in staat is adequaat te handelen in situaties die specifiek zijn voor de beroepspraktijk. ${ }^{1011}$ Aan deze opvatting van competentie zijn twee belangrijke componenten te onderscheiden. Eén component wordt gevormd door het geheel aan situaties dat de beroepspraktijk weerspiegelt (het domein), de andere omvat de kennis, vaardigheden en attitudes die noodzakelijk zijn om bepaalde taken correct te verrichten. Bij beoordeling van competentie gaat het er dan om dat beoordeeld wordt of studenten in specifieke situaties de juiste kennis, vaardigheden en attitudes kunnen toepassen en daarbij effectief en efficiënt kunnen handelen. Dit betekent dat in kwalificerende examens de nadruk zou moeten liggen op toetsvormen waarbij sprake is van geïntegreerde toepassing van kennis, vaardigheden, inzicht en attitudes in situaties die een afspiegeling vormen van de beroepspraktijk.

In het medisch onderwijs is een aantal toetsvormen ontwikkeld voor de beoordeling van klinische competentie. Een toetsvorm waarin de mogelijkheid van objectieve beoordeling gekoppeld kan worden aan een hoge mate van validiteit (hoog realiteitsgehalte) en praktische toepasbaarheid, is het stationsexamen. Stationsexamens zijn gebaseerd op het eind jaren zeventig ontwikkelde objective structured clinical examination (OSCE) en de standardized patient-based test. 1213 In een stationsexamen doorlopen studenten een circuit van verschillende stations. Elk station wordt gevormd door een aparte ruimte waarin de student gevraagd wordt om bepaalde, klinisch relevante opdrachten uit te voeren. De duur van de stations kan variëren van vijf tot dertig minuten. In een stationsexamen kunnen zowel kennis als vaardigheidselementen aan bod komen. Afhankelijk van de inhoud van de stations kunnen gestandaardiseerde patiënten worden ingezet om bepaalde klachten of problemen te simuleren. 
Beoordeling van studenten kan plaatsvinden op basis van directe observatie en aan de hand van voorgestructureerde beoordelingslijsten die door (getrainde) observatoren worden ingevuld. Ook is het mogelijk dat bepaalde opdrachten schriftelijk afgehandeld worden. Stationsexamens hebben in het medisch onderwijs een grote vlucht genomen en worden beschouwd als stateof-the-art bij het toetsen van complexere vaardigheden. ${ }^{14}$ Op grond van de veelbelovende resultaten in het medisch onderwijs werd deze toetsvorm gekozen als uitgangspunt bij de ontwikkeling van de VCT aan de VVS. Alvorens deze verloskundige competentietoets te beschrijven, is het zinvol het begrip 'verloskundige competentie' nader te definiëren.

\section{Verloskundige competentie}

Centraal in het professioneel handelen van de verloskundige staat de begeleiding van zwangerschap, baring en kraambed. Daarbij wordt in Nederland een duidelijke scheidslijn aangebracht tussen fysiologie en pathologie. Uitgangspunt hierbij is dat zwangerschap, bevalling en kraambed in principe fysiologische processen zijn. De verloskundige in de eerste lijn begeleidt de gezonde zwangerschap. Verwijzing naar de tweede lijn vindt plaats in geval van obstetrische pathologie en bepaalde gevallen van verhoogd verloskundig risico. Deze voortdurende screening, de zogenaamde risicoselectie, vindt plaats door verloskundigen en vormt de pijler van het verloskundig zorgsysteem in Nederland. 1516 In deze context omvat verloskundige competentie bekwaamheden met betrekking tot:

1. het verzamelen van relevante gegevens op basis van anamnese, fysisch-diagnostisch onderzoek, laboratoriumonderzoek, et cetera;

2. interpretatie van gegevens in het kader van het opstellen van werkhypothesen en risicoselectie;
3. het kiezen en uitvoeren van het juiste beleid op basis van de bevindingen;

4. het geïntegreerd kunnen toepassen van relevante kennis, vaardigheden en attitudes en het inzicht om te komen tot effectief en efficiënt handelen in de verloskundige beroepspraktijk. De verloskundige dient daarbij in staat te zijn op een effectieve wijze haar bevindingen aan cliënten en/of andere hulpverleners mee te delen en over het te voeren beleid te overleggen met cliënt en/of andere hulpverleners.

Deze beschrijving van verloskundige competentie komt sterk overeen met beschrijvingen van klinische competentie in andere gezondheidszorgberoepen, zoals verpleegkunde en geneeskunde. ${ }^{9} 12 \quad 17$ Overigens moet opgemerkt worden dat verloskundige competentie een breed terrein aan kennis, vaardigheden, bekwaamheden en attitudes omvat. Centraal in dit artikel staat de verloskundige competentie in situaties die betrekking hebben op het verloskundig handelen in de begeleiding van zwangerschap, baring en kraambed. Andere zaken, zoals praktijkvoering, samenwerking met collega's, intercollegiale toetsing, bij- en nascholing en onderzoeksactiviteiten, blijven hier buiten beschouwing.

\section{De Verloskundige CompetentieToets aan de Vroedvrouwenschool}

De VCT aan de VVS is een stationsexamen waarbij aan de hand van realistische problemen uit de verloskundige beroepspraktijk de competentie van student-verloskundigen beoordeeld wordt.

\section{Ontwikkeling, productie en samenstelling}

De VCT bestaat uit zes stations. De inhoud van de stations vormt een afspiegeling van de opleidingsdoelstellingen met betrekking tot verloskundige competentie in een drietal domeinen: 
- verloskundig handelen tijdens de prenatale periode (zwangerschap);

- verloskundig handelen tijdens de natale periode (baring);

- verloskundig handelen tijdens de postnatale periode (kraambed en neonatologie). Per domein worden twee stations in de toets opgenomen. Een voorbeeld van de samenstelling van een VCT is opgenomen in figuur 1.

In elk station wordt aan de student een verloskundige casus gepresenteerd. Aan de student wordt gevraagd zonodig aanvullende gegevens te verzamelen, deze te interpreteren en het verloskundig beleid hierop af te stemmen en uit te voeren. Communicatievaardigheden vormen een geïntegreerd onderdeel van één of meer stations. Verloskundig-technische handelingen worden verricht op fantomen. Simulatiecliënten worden op beperkte schaal ingezet, voornamelijk in stations waar communicatievaardigheden worden getoetst.

De specifieke inhoud van een verloskundige competentietoets wordt vastgesteld aan de hand van een toetsmatrijs. Deze toetsmatrijs bestaat uit een lijst van onderwerpen (verloskundige casus) verdeeld over de drie domeinen. De onder- werpenlijst is tot stand gekomen op basis van verloskundige problemen uit de praktijk en de inhoud van het opleidingsprogramma. Voor de samenstelling van een VCT wordt steeds per domein een nieuwe selectie gemaakt uit deze onderwerpen.

De ontwikkeling van de stations vindt plaats door de vaste staf van de opleiding. Een daartoe ingestelde toetsbeoordelingscommissie, samengesteld uit de vaste docentenstaf, bewaakt de kwaliteit van de toets: zij bepaalt de samenstelling van de toets aan de hand van de toetsmatrijs en beoordeelt de aangeleverde stations op inhoudelijke en vormtechnische punten zowel vóór als na de afname van het station. Revisie van stations gebeurt mede op basis van feedback door externe, praktiserend verloskundigen.

De prestaties van de student worden in elk station beoordeeld door twee observatoren. Eén observator vervult de rol van cliënt en beoordelaar. Hij beschikt daarbij over gestructureerde protocollen ten behoeve van de volgorde en wijze van informatieverstrekking aan de student en de scoring van de geleverde prestaties (figuur 2 toont een voorbeeld van een deel van een scoringsprotocol).

Figuur 1. Samenstelling Verloskundige CompetentieToets jaar 4, 1997-1998.

\begin{tabular}{|c|c|c|}
\hline Domein & Stationnummer & Verloskundige casuïstiek \\
\hline Prenatale periode & 1 & Liggingsafwijking (stuitligging) \\
\hline Prenatale periode & 2 & $\begin{array}{l}\text { Kwalen en kwaaltjes tijdens zwangerschap } \\
\text { (Hb-daling; oedeem) }\end{array}$ \\
\hline Natale periode & 4 & Handelen in noodsituaties (uitgezakte navelstreng) \\
\hline Natale periode & 5 & Indalingsstoornissen (hoge rechtstand) \\
\hline Postnatale periode & 3 & Kraambed (trombo-embolische processen) \\
\hline Postnatale periode & 6 & Neonatologie (defaecatieproblemen) \\
\hline
\end{tabular}


Figuur 2. Voorbeeld van een obstervatorprotocol.

Instructie aan de student (inleidende casus):

Je ziet op het intake spreekuur mw. Van Waardenburg. Mw. is een Nederlandse vrouw van 27 jaar, G2, P1, A0. Zij is in december 1996 thuis bevallen van een zoon van 3500 gram bij een amenorroeduur van 39+4 weken. Zwangerschap, baring en kraambed zijn zonder problemen verlopen; mevrouw heeft gedurende drie maanden volledig borstvoeding gegeven. Nu is mevrouw weer zwanger. Haar laatste menstruatie was op 10 maart 1999.

1. Vraag

Je neemt bloed af bij mevrouw. Welke bloedonderzoeken voer je uit of vraag je aan op het lab.-formulier?

Scoringsprotocol

Goed:

bloedgroep; Rhesusfactor; HbsAg; IEA; Lues; $\mathrm{Hb}$ (Rubella antistoffen en $\mathrm{Ht}$ zijn in eerste lijn niet gebruikelijk, maar zijn niet fout)

Voldoende: $\quad$ student noemt vijf onderzoeken

Matig: $\quad$ student noemt vier onderzoeken

Onvoldoende: minder dan vier onderzoeken

Student krijgt formulier waarop laboratoriumuitslagen staan vermeld.

2a. Vraag

Interpreteer de uitslagen en geef een toelichting bij je antwoord.

Scoringsprotocol

Goed:

er is sprake van een te laag $\mathrm{Hb}$ en dus van een anemie. Aangezien de vrouw van Nederlandse afkomst is, is ijzergebreksanemie de meest waarschijnlijke diagnose. Mevrouw is Rhesus-negatief. Dit kan aanleiding zijn tot problemen in verband met mogelijk rhesus-antagonisme.

Voldoende: $\quad$ juiste diagnose, zonder nadere toelichting

Matig: benoemt alleen laag $\mathrm{Hb}$ /anemie of rhesus-antagonisme

Onvoldoende: alle andere antwoorden

2b. Vraag

Formuleer op basis van de interpretatie van de lab-uitslagen je beleid.

Scoringsprotocol

Goed:

a. voorschrijven van ijzersuppletie

b. zorgen dat zo snel mogelijk gestart wordt met ijzersuppletie

c. voorschrijven in eerste instantie voor zes weken

d. na zes weken $\mathrm{Hb}$-controle

e. nagaan of bloedgroep eerste kind is bepaald, wat deze is en zonodig nagaan of $\mathrm{mw}$. anti-D heeft ontvangen

f. rond week 30 bloedafname ter bepaling van rhesus-antilichamen

g. direct na geboorte navelstrengbloed afnemen ter bepaling bloedgroep kind

Voldoende: $\quad$ noemt a., b., f., g. en $\mathrm{h}$.

Matig: noemt a. en $\mathrm{f}$.

Onvoldoende: alle andere antwoorden.

Observator mag hier toevoegen dat het gaat om het beleid in de gehele zwangerschap, baring en kraambed. 
In elk station wordt de student beoordeeld op de volgende aspecten:

- verkrijgen van relevante aanvullende informatie (anamnese en onderzoek);

- interpretatie van gegevens, vaststellen van te voeren beleid (risicoselectie en beleid);

- benoemen van achterliggende kenniselementen, relevant voor het oplossen van het probleem (theoretische achtergronden);

- verloskundig-technische vaardigheden/ communicatievaardigheden.

De beoordeling wordt voor elk van deze aspecten afzonderlijk vastgelegd op een criteriumlijst (figuur 3).
Het oordeel over de prestatie van de kandidaat op een bepaald station komt tot stand op basis van consensus tussen de beide beoordelaars. Simulatiecliënten treden niet op als beoordelaar van de student. De observatoren zijn voor een deel afkomstig uit de vaste staf van de opleiding; een groot deel van de observatoren wordt extern geworven (merendeels eerstelijns werkende verloskundigen). Voorafgaand aan de toetsafname vinden trainingsbijeenkomsten plaats voor de observatoren. Tijdens deze bijeenkomsten wordt met name geoefend in het hanteren van het scoringsprotocol en worden afspraken gemaakt over te volgen procedures bij de afname van de toets.

Figuur 3. Voorbeeld van een criteriumlijst.

\begin{tabular}{|c|c|c|c|c|c|c|}
\hline Verloskundige competentietoets & G & $\mathrm{V}$ & M & $\mathrm{O}$ & $\mathrm{F}$ & $\mathrm{N}$ \\
\hline Stationnummer & O & $\mathrm{O}$ & A & $\mathrm{N}$ & $\mathrm{O}$ & I \\
\hline Datum & $\mathrm{E}$ & $\mathrm{L}$ & $\mathrm{T}$ & $\mathrm{V}$ & $\mathrm{U}$ & $E$ \\
\hline Studentnummer & D & D. & I & $\mathrm{O}$ & $\mathrm{T}$ & $\mathrm{T}$ \\
\hline Naam student & & & G & $\mathrm{L}$ & & \\
\hline Naam observatoren & & & & D. & & \\
\hline \multicolumn{7}{|l|}{ ZWANGERSCHAP } \\
\hline \multicolumn{7}{|l|}{ Anamnese/onderzoek } \\
\hline 1. Welke bloedonderzoeken voer je uit of vraag je aan? & 0 & 0 & 0 & 0 & 0 & 0 \\
\hline \multicolumn{7}{|l|}{ 6. Welke aanvullende informatie wil je nu hebben om tot een } \\
\hline beleid te komen? & 0 & 0 & 0 & 0 & 0 & 0 \\
\hline \multicolumn{7}{|l|}{ Beleid en risicoselectie } \\
\hline 2 a. Interpreteer de uitslagen en licht de interpretatie toe. & 0 & 0 & 0 & 0 & 0 & 0 \\
\hline 2 b. Formuleer je beleid. & 0 & 0 & 0 & 0 & 0 & 0 \\
\hline \multicolumn{7}{|l|}{ 7. Wat is op grond van de informatie die je nu hebt je beleid? } \\
\hline Licht dit toe. & 0 & 0 & 0 & 0 & 0 & 0 \\
\hline \multicolumn{7}{|l|}{ Theoretische achtergronden } \\
\hline \multicolumn{7}{|l|}{ 4. Anemie bij zwangeren: welke classificaties ken je en welke zijn } \\
\hline \multicolumn{7}{|l|}{ 5. Welke zijn mogelijke gevolgen voor de foetus bij rhesus- } \\
\hline \multicolumn{7}{|l|}{ Vaardigheid } \\
\hline 3. Beheerst de vaardigheid uitschrijven van recept. & 0 & 0 & 0 & 0 & 0 & 0 \\
\hline
\end{tabular}




\section{Organisatie}

Alle studenten in de leerjaren 3 en 4 van de opleiding tot verloskundige nemen verplicht deel aan de VCT, gemiddeld veertig studenten per leerjaar. Voor iedere toets wordt een circuit van zes stations georganiseerd. De duur van elk station is dertig minuten, zodat de totale toetsduur drie uur bedraagt. De toets wordt afgenomen op twee dagen, waarbij studenten per dag drie stations doorlopen. De samenstelling van het circuit is voor alle studenten in een bepaald leerjaar identiek. Om fraude te voorkomen worden de groepen studenten die op verschillende tijdstippen het circuit doorlopen, strikt gescheiden gehouden.

\section{Zak/slaagnormen}

De score van studenten op de afzonderlijke stations wordt uitgedrukt in een percentage van het maximaal te behalen aantal punten. Elk station wordt apart beoordeeld. Per domein worden de stations voor de totstandkoming van het eindoordeel over het betreffende domein onderling gemiddeld. De eindbeoordeling van de totale VCT resulteert in een voldoende indien alle domeinen met een voldoende zijn beoordeeld.

Prestaties van studenten op de VCT worden beoordeeld op basis van een relatieve norm (gemiddelde totaalscore van de jaargroep minus één standaarddeviatie),

Figuur 4. Voorbeeldformulier ten behoeve van student.

Studentnummer

Naam student

Verloskundige CompetentieToets

Jaargroep

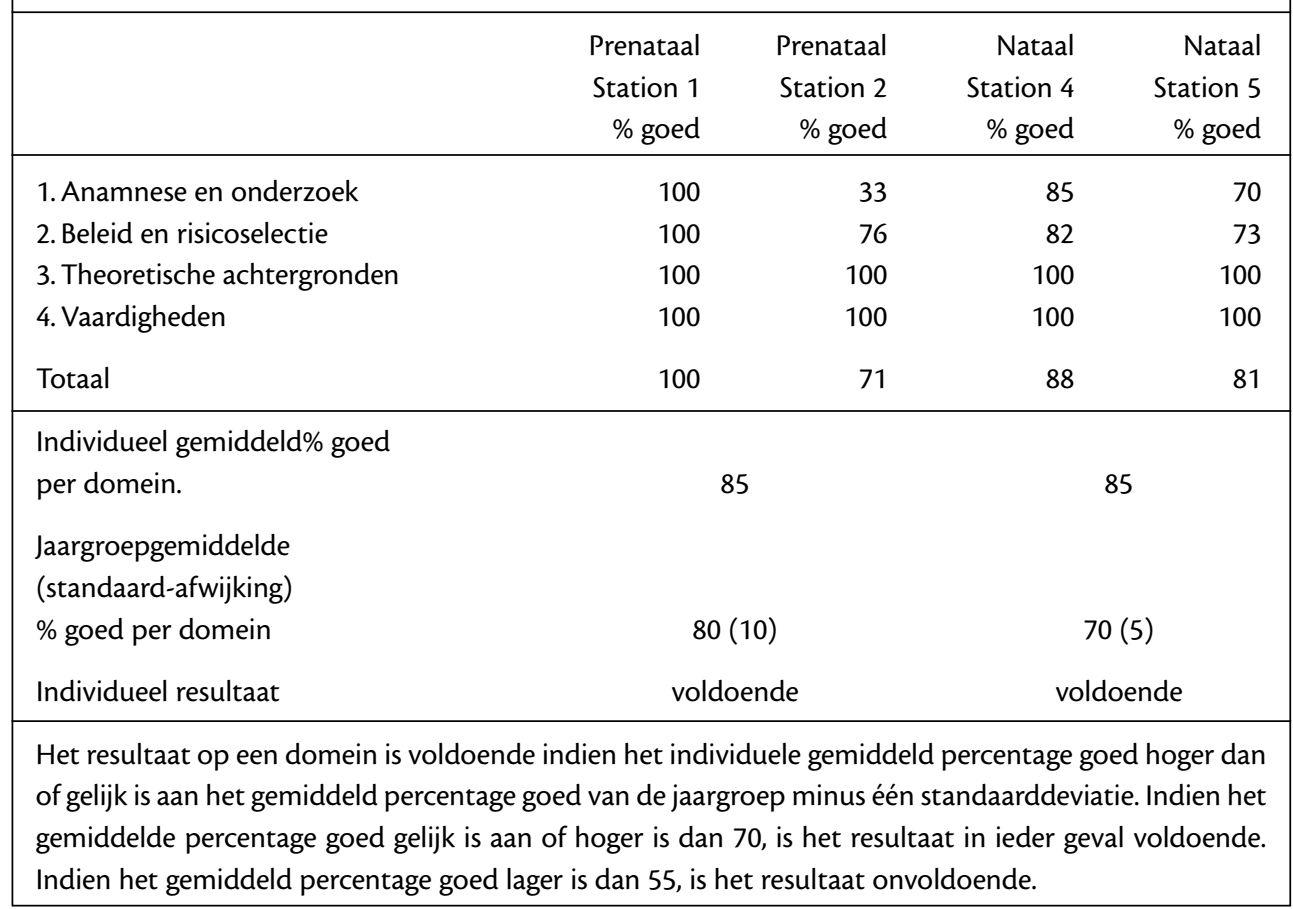


waarbij absolute boven- en ondergrenzen worden gehanteerd bij de vaststelling van de zak/slaaggrenzen. Terugrapportage aan de student vindt schriftelijk plaats. Een voorbeeld van een rapportageformulier is weergegeven in figuur 4 .

\section{Beschouwing}

Ontevredenheid over gehanteerde beoordelingsmethoden, met name bij de beoordeling van studenten aan het eind van de opleiding, heeft aan de VVS geleid tot de ontwikkeling van een alternatieve methode voor beoordeling van verloskundige competentie. Op grond van ontwikkelingen en onderzoek in met name geneeskundeonderwijs is gekozen voor de opzet van een stationsexamen. Bij de vormgeving van de toets is uitgegaan van de randvoorwaarden voor de VVS en specifieke kenmerken van verloskundig handelen. Onderzoek naar betrouwbaarheid en validiteit van de toets is recent gestart. Op basis van mondelinge en schriftelijke evaluaties verkrijgt de opleiding inzicht in de waarde van de toets zoals gepercipieerd door studenten, docenten en externe observatoren. De eerste ervaringen met de beschreven opzet van toetsing van verloskundige competentie zijn daarbij overwegend positief. Zowel docenten als studenten waarderen de verloskundige competentietoets vanwege het hogere realiteitsgehalte en de relevantie van de toetsinhoud voor de verloskundige praktijk. De studenten geven aan dat deze toets minder dan de kennistoetsen aan de opleiding een beroep doet op memoriseren en herkenning van feiten. Zij worden aangezet tot leergedrag dat meer gericht is op toepassing van kennis in de praktijk. Ook naar de mening van docenten wordt de doelstelling van de toets, namelijk dat verloskundige competentie zou moeten blijken uit integratie van kennis en vaardigheden en het inzicht om deze toe te passen in situaties uit de verloskundige praktijk, steeds beter bereikt.

De toenemende ervaring en systematische kwaliteitsevaluatie leiden tot een voortdurende verbetering van structuur en inhoud van de stations. Naast het vaststellen van welke elementen van verloskundige competentie getoetst moeten worden, zijn de belangrijkste aandachtspunten daarbij het vaststellen van de relevantie van de beoordelingscriteria en de mate van detaillering van de criteria en beoordelingsprotocollen. De gevoerde discussies over verloskundige competentie en de terugkoppeling die de opleiding ontvangt op basis van de toetsprestaties van studenten, hebben daarnaast positief sturende effecten op de inhoud en de opzet van het opleidingscurriculum.

Naast deze positieve ervaringen zijn er ook knelpunten te signaleren. De voorbereidingstijd van studenten is soms lang, hetgeen kan interfereren met andere studieactiviteiten. Deels hangt dit samen met het feit dat de toets deel uitmaakt van het examen. Mogelijk is ook de aansluiting van het onderwijs op deze toetsmethode nog niet optimaal.

Een ander probleem is het relatief hoge aantal studenten dat zakt voor de toets (25-30\%). De wijze waarop het eindoordeel tot stand komt, speelt daarbij waarschijnlijk een belangrijke rol. Compensatiemogelijkheden tussen stations zijn (mogelijk ten onrechte) beperkt. Daarnaast is uit onderzoek bekend dat het lastig is de moeilijkheidsgraad van toetsen van tevoren adequaat in te schatten. ${ }^{18} \mathrm{Dit}$ blijkt ook bij de VCT het geval te zijn. In 1997-1998 varieerden de gemiddelde scores op de afzonderlijke stations voor het vierde leerjaar van $62,9 \%$ tot $88,2 \%$. Dit gegeven rechtvaardigt het hanteren van relatieve zak/slaaggrenzen, maar het illustreert tevens de noodzaak van betere kwaliteitscontrole van de stations voor en 
na afname. In de ontwikkelingsfase van de stations is het 'proefdraaien' van stations daarbij een belangrijke stap.

Belangrijkste knelpunt wordt evenwel gevormd door de hoge kosten van de toets. De te leveren investering in de ontwerpfase van de stations, de voorbereiding van het schriftelijke materiaal en de training van observatoren is moeilijk op te brengen voor een opleiding met een geringe stafbezetting. Een mogelijke oplossing voor dit probleem zou gevonden kunnen worden in samenwerking met andere verloskundige opleidingen. Op basis van de ervaringen tot nog toe lijkt de VCT een waardevolle aanvulling bij de beoordeling van competentie in de opleiding tot verloskundige. Deze toetsvorm lijkt het mogelijk te maken om verloskundige competentie op een objectieve manier te toetsen, waarbij tegelijkertijd validiteitsaspecten en praktische toepasbaarheid gewaarborgd kunnen worden.

\section{Literatuur}

1. McGaghie WC. Professional competence evaluation. Educational Researcher 1991;20(1):3-9.

2. Hager P, Butler J. Two models of educational assessment. Assessment and Evaluation in Higher Education 1996;21(4):367-78.

3. Sluijsmans D, Dochy F. Alternatieve toetsmethoden in studentgericht onderwijs. Tijdschrift voor Hoger Onderwijs 1998;16(4):298-314.

4. Newble DI, Jaeger K. The effects of assessments and examinations on the learning of medical students. Med Educ 1983;17:165-71.

5. Newble D, Jolly B, Wakeford RE. The certification and recertification of doctors: issues in the assessment of clinical competence. Cambridge: Cambridge University Press; 1994.

6. Vleuten $C$ van der, Newble D, Case S, Holsgrove G, McCann B, McRae C, Saunders N. Methods of assessment in certification. In: Newble D, Jolly B, Wakeford RE, redactie. The certification and recertification of doctors: issues in the assessment of clinical competence. Cambridge: Cambridge University Press; 1994. p. 105-25.

7. Vleuten CPM van der. The assessment of professional competence: developments, research and practical implications. Advances in Health Sciences Education 1996;1:41-67.
8. Ross M, Carrol G, Knight J, Chamberlain M, Fothergill-Bourbonnais F, Linton J. Using the OSCE to measure clinical skills performance in nursing. Journal of Advanced Nursing 1988; 13:45-56.

9. McKnight J, Rideout E, Brown B, Ciliska D, Patton D, Rankin J, Woodward C. The Objective Structured Clinical Examination: an alternative approach to assessing student clinical performance. Journal of Nursing Education 1987;26(1):3941.

10. Kane MT. The assessment of professional competence. Evaluation \& the Health Professions 1992; 15(2):163-82.

11. Hager P, Gonczi A. What is competence? Med Teach 1996;18(1):15-8.

12. Harden RM, Gleeson FA. ASME Medical Education Booklet no. 8: Assessment of medical competence using an objective structured clinical examination (OSCE). Med Educ 1979;13:39-54.

13. Stillman PL, Ruggill JS, Rutala PJ, Sabers DL. Patient instructors as teachers and evaluators. J Med Educ 1980;55:186-93.

14. Luijk SJ van. Toetsen van vaardigheden door middel van het stationsexamen. Bulletin Medisch Onderwijs 1996;15:140-54.

15. Crébas A. Beroepsomschrijving verloskundigen. Beroepsomschrijving opgesteld in opdracht van de Nederlandse Organisatie van Verloskundigen. Bilthoven; 1989.

16. Commissie Herziening Curriculum Opleiding tot Verloskundige. Herziening curriculum opleiding tot verloskundige. Advies van de CHCOV. Rijswijk: Ministerie van WVC; 1991.

17. Norman GR. Defining competence: a methodological review. In: Neufeld V, Norman GR, redactie. Assessing clinical competence. New York: Springer Publishing Company; 1985. p. 15-33.

18. Berkel HJM van. De diagnose van toetsvragen [proefschrift]. Amsterdam: Universiteit van Amsterdam; 1984.

De auteurs:

M.J.B. Govaerts, arts, is verbonden aan de Capaciteitsgroep Onderwijsontwikkeling en Onderwijsresearch, Universiteit Maastricht.

Dr. L.W.T. Schuwirth, arts, is als medisch onderwijskundige verbonden aan de Capaciteitsgroep Onderwijsontwikkeling en Onderwijsresearch, Universiteit Maastricht.

Prof. dr. C.P.M. van der Vleuten, psycholoog, is hoogleraar en voorzitter van de Capaciteitsgroep Onderwijsontwikkeling en Onderwijsresearch, Universiteit Maastricht.

A.K. Pin is als onderwijsmedewerker en coördinator vaardigheidsonderwijs verbonden aan de Vroedvrouwenschool te Kerkrade. 
M.E.J. Clement, verloskundige, is als coördinator theoretisch onderwijs verbonden aan de Vroedvrouwenschool te Kerkrade.

\section{Correspondentieadres:}

M.J.B. Govaerts, Capaciteitsgroep Onderwijsontwikkeling en Onderwijsresearch, Universiteit Maastricht, Postbus 616, 6200 MD Maastricht.

E-mail:m.govaerts@educ.unimaas.nl.

\section{Summary}

Over the last few decades teaching and assessment of professional competence have received more and more attention in higher education. Increasing dissatisfaction with traditional assessment strategies has resulted in the introduction of assessment procedures that reflect actual professional performance (performance-based assessment). An important factor in the shift towards performance-based assessment is the awareness that student learning is primarily test driven. At the Kerkrade School of Midwifery a performance-based test was developed and implemented as part of the final examinations. This test was designed to assess student-midwives' professional competence in an integrated manner. The present paper describes the development and implementation of and student and staff experiences with the Midwifery Competence Test (MCT).(Govaerts MJB, Schuwirth LWT, Vleuten CPM van der, Pin AK, Clement MEJ. A test for the assessment of midwifery competence. Dutch Journal of Medical Education 2000;19(4):119-28) 